\title{
Urinary creatinine and hydroxyproline in relation to childhood malnutrition
}

\author{
By D. S. McLAREN, HERMINE LOSHKAJIAN AND A. A. KANAWATI \\ Nutrition Research Program, School of Medicine, American University \\ of Beirut, Beirut, Lebanon
}

(Received I8 September 1969-Accepted 2 March 1970)

\begin{abstract}
I. Urinary excretions of creatinine (Cre) and hydroxyproline (OHPr) were measured in two groups of children: (a) $24 \mathrm{~h}$ collections in male and 'spot' samples in female marasmic infants throughout the course of treatment, and $(b)$ 'spot' samples in underprivileged preschool children at home. Results were related to certain somatic measurements and in some instances to some dietary factors.

2. Analysis of $24 \mathrm{~h}$ samples taken at intervals throughout $120 \mathrm{~d}$ of treatment showed a steady rise towards normal levels from very low initial values of OHPr. There was no correlation with age or body-weight on admission, nor of OHPr excretion through recovery with increase in height. Excretion of Cre also increased during recovery but the trend was more erratic. There was no relation to initial weight deficit or age but mean Cre excretion through recovery did correlate with rate of increase in weight. Values of Cre excretion at different stages of recovery expressed in terms of weight or height differed somewhat from those reported by others. The possible significance of these findings is discussed.

3. High correlations of the OHPr index according to Whitehead ( 1965 ) determined on $6 \mathrm{~h}$ and $24 \mathrm{~h}$ collections provided evidence for the representative nature of 'spot' samples.

4. Partial correlation analysis of body-weight and urine volume in relation to Cre excretion $(\mathrm{mg} / 24 \mathrm{~h})$ showed that the former $(r=0.719)$ had a greater influence than the latter $(r=0.485)$.

5. In a subgroup of eleven marasmic infants aged 3-5 months multiple linear regression analyses of OHPr and Cre excretion on somatic and dietary factors revealed no consistent correlations.

6. Periods of lowered OHPr and Cre excretion were frequent but in only half of the instances were they related to intercurrent infection.

7. A high correlation was found between changes in excretion of OHPr and of Cre throughout recovery.

8. An appraisal was made of the OHPr index according to Whitehead (I965). On the basis of the considerable influence that age was shown to have on this index during the preschool period an OHPr index (age-adjusted) was suggested for use.

9. The OHPr index (age-adjusted) determined on 'spot' samples from underprivileged preschool children at home and from marasmic infants during recovery was shown to be closely correlated with a modified 'index of thriving' based on somatic measurements.

Io. The value of Cre and OHPr determinations in the study of severely malnourished children during recovery and in the detection of mild undernutrition is discussed in the light of these experimental results.
\end{abstract}

We have been interested for some years in the problem of defining the various clinical forms of protein-calorie malnutrition (P-CM) (McLaren, Pellett \& Read, I 967 ). We have also attempted to identify marginal malnutrition in childhood by an 'index of thriving' based on four somatic measurements (weight, height, head circumference, mid-arm circumference) for the study of what we call 'failure to thrive' among preschool children in a community (Kanawati, McLaren \& Abu-Jawdeh, 1970). In 1965 we reported that, where the marasmic type of P-CM predominated, the amino acid ratio of Whitehead ( 1964 ) was not of value in the field (McLaren, Kamel \& Ayyoub, 1965). Whitehead (1965) showed that, as in other forms of growth 
retardation, the excretion of hydroxyproline (OHPr) was reduced in both marasmus and kwashiorkor. What was termed the OHPr index was introduced with the idea of using the test in the field on 'spot' samples of urine from children of unknown age. It is expressed as follows:

$$
\frac{\mathrm{m} \text {-moles OHPr } / 1}{\mathrm{~m} \text {-moles creatinine } / 1 \text { per kg body-weight }}=\frac{\mathrm{m} \text {-moles OHPr } / 1 \times \text { body-weight }(\mathrm{kg})}{\mathrm{m} \text {-moles creatinine } / \mathrm{l}} \text {. }
$$

The theoretical basis of this index is here criticized and an alternative means of expression is proposed.

During the past 2 years the study of infants recovering from severe marasmus over a period of several months in our metabolic unit, and also field investigations of ' failure to thrive' have provided opportunities for measuring urinary excretion of OHPr and creatinine (Cre) and relating the results obtained to other measurements of nutritional status and growth.

\section{EXPERIMENTAL}

Urinary excretions of OHPr and Cre were studied in two groups of subjects: (a) infants recovering in hospital from severe marasmus provided $24 \mathrm{~h}$ collections of urine, and $(b)$ underprivileged preschool children at home from whom 'spot' samples of urine were obtained.

\section{Marasmic infants}

The clinical studies took place in the Clinical Nutrition Unit of this Department, a metabolic unit with ten paediatric beds attached to the Solarium of Lebanon Hospital, Beirut. The subjects were nineteen male and ten female patients (age range $3^{-17}$ months on admission) with severe marasmus, as defined by our Simple Scoring System (McLaren et al. 1967). On admission their mean weight for age (actual/Boston standard \%) was $53 . \circ \%$. In the majority, after 4 months of treatment, the weight had closely approached the expected weight for height (mean $97.8 \%$ ), although not for age. Our practice has been to admit patients to the Unit from the hospital as soon as imbalance of fluid and electrolytes has been corrected and infections controlled. On admission and at regular intervals during recovery (every $\mathrm{I}_{5} \mathrm{~d}$ during the first $60 \mathrm{~d}$ and thereafter at intervals of $3 \circ \mathrm{d}$ ) somatic measurements were made and urinary OHPr and Cre were determined. Somatic measurements made were: weight, length, crownsymphysis, symphysis-sole, head circumference, chest circumference, mid-arm circumference, muscle mid-arm circumference, skinfold thickness (biceps, triceps, scapula and umbilicus) with the Harpenden callipers. The techniques used were in accordance with the recommendations of Jelliffe (1966). Collections of urine $(24 \mathrm{~h})$ were obtained from boys, and in some instances 6-hourly collections were also made to study diurnal variations. The relationship between urine volume and Cre excretion was investigated in $24 \mathrm{~h}$ collections. Urinary OHPr excretion was measured by the method of Kivirikko, Laitinen \& Prockop (1967) and Cre by that of Taussky (1956). All OHPr determinations were made by one of us (H. L.) as were those of Cre with the supervised assistance of a technician. Urine samples were acidified and stored under toluene at $-4^{\circ}$ until used. 'Spot' samples only were obtained from girls. 
For a subgroup of eleven male infants aged $3-5$ months mean values for certain dietary factors were calculated from daily records of body-weight and food intake. These factors were: calorie intake/kg body-weight per d; protein intake $/ \mathrm{kg}$ bodyweight per $d$; and calorie: protein ratio. Linear regression analyses were carried out on all these factors. Only the results related to excretion of OHPr and Cre are given here. The significance of diminished excretion of OHPr and Cre and the effect of intercurrent infections were also investigated in this subgroup.

No sufficiently well-nourished children were available in the hospital to act as control subjects. Thirteen apparently healthy children from whom urine samples were obtained each had an index of thriving (see below) which was outside the range which we set for healthy controls.

\section{Preschool children at home}

The OHPr and Cre concentrations (m-moles/l) were determined on 'spot' urine samples from fifty-seven children (age range 4-52 months) obtained in the course of field studies. The ages of these children were accurately known. For reasons that will

\section{Table I. Derivation of the index of thriving for the children}

$\begin{array}{lcc}\text { Measurement } & \text { Percentage range } & \text { Score } \\ \text { Weight } & \text { I00 and above } & \text { o } \\ & 90-100 & \text { I } \\ & 80-90 & 2 \\ 70-80 & 3 \\ & 60-70 & 4 \\ \text { Height } & 60 \text { and less } & 5 \\ & 100 \text { and above } & 0 \\ & 90-100 & 1 \\ & 85-90 & 2 \\ \text { Head circumference } & 80-85 & 3 \\ & 80 \text { and less } & 4 \\ & 100 \text { and above } & 0 \\ & 90-100 & 1 \\ & 85-90 & 2 \\ & 80-85 & 3 \\ \text { Mid-arm circumference } & 80 \text { and less } & 4 \\ & 100 \text { and above } & 0 \\ & 90-100 & 1 \\ & 80-90 & 2 \\ & 70-80 & 3 \\ & 60-70 & 4 \\ & 60 \text { and less } & 5\end{array}$

Values are compared with standards; Boston for weight, height, head circumference (Stuart $\&$ Stevenson, 1959), Wolanski for mid-arm circumference (Jelliffe, 1966). The index of thriving for any subject is calculated by summing the four scores. A healthy child developing normally has an index 0-2; a child with 'failure to thrive' 9 or above.

be explained on p. 646 the age of the subject was taken into account in expressing the results, giving rise to an $\mathrm{OHPr}$ index (age-adjusted). This was compared with the index of thriving for the same children, derived as shown in Table $\mathrm{I}$. As the index of thriving also is influenced by body-weight, the score derived from weight was excluded for the present purpose in calculating the modified index of thriving. 


\section{RESULTS}

\section{OHPr and Cre excretion during recovery from marasmus}

Absolute $\mathrm{OHPr}$ and Cre excretion. The urinary excretion of $\mathrm{OHPr}(\mathrm{mg} / 24 \mathrm{~h})$ throughout recovery in nineteen male patients is shown in Table 2. Values were extremely low initially, the normal being $42 \cdot 9$ ( $\mathrm{SD} \pm 9^{\cdot 8}$ ) for this age group (Younoszai,

Table 2. Hydroxyproline and creatinine $(\mathrm{mg} / 24 \mathrm{~h})$ in marasmic male infants aged $3^{-17}$ months on admission

\begin{tabular}{|c|c|c|c|c|c|c|c|}
\hline \multirow[b]{2}{*}{$\begin{array}{l}\text { Time after admis- } \\
\text { sion (d) }\end{array}$} & \multicolumn{6}{|c|}{ (Mean values with their standard errors and, in parentheses, ranges) } & \multirow[b]{2}{*}{120} \\
\hline & 0 & 15 & $3^{\circ}$ & 45 & 60 & 90 & \\
\hline No. of patients & I9 & 17 & I9 & 19 & 17 & 17 & Io \\
\hline OHPr excretion & $\begin{array}{l}\text { I } 2 \cdot 7 \pm I \cdot 4 \\
(4 \cdot 4-22 \cdot 9)\end{array}$ & $\begin{array}{l}I 3 \cdot 4 \pm I \cdot 5 \\
(5 \cdot 2-24 \cdot 4)\end{array}$ & $\begin{array}{l}19 \cdot 5 \pm r \cdot 8 \\
(6 \cdot 1-33 \cdot 2)\end{array}$ & $\begin{array}{l}23 \cdot 0 \pm 2 \cdot 4 \\
(7 \cdot 3-45 \cdot 7)\end{array}$ & $\begin{array}{l}32 \cdot 6 \pm 3 \cdot 1 \\
(7 \cdot 6-54 \cdot 8)\end{array}$ & $\begin{array}{c}35 \cdot 5 \pm 3 \cdot 3 \\
(11 \cdot 4-65 \cdot 7)\end{array}$ & $\begin{array}{c}39 \cdot 1 \pm 3 \cdot 7 \\
(15 \cdot 1-58 \cdot I)\end{array}$ \\
\hline Cre excretion & $\begin{array}{c}45 \cdot 7 \pm 2 \cdot 7 \\
(28 \cdot 4-69 \cdot 0)\end{array}$ & $\begin{array}{c}49 \cdot 3 \pm 3 \cdot 6 \\
(27 \cdot 3-75 \cdot 0)\end{array}$ & $\begin{array}{c}65 \cdot 9 \pm 4 \cdot 4 \\
(39 \cdot 6-121 \cdot 8)\end{array}$ & $\begin{array}{c}63 \cdot 2 \pm 4 \cdot 7 \\
(33 \cdot 0-117 \cdot 9)\end{array}$ & $\begin{array}{c}73 \cdot 6 \pm 4 \cdot 8 \\
(48 \cdot 6-\text { I I I } \cdot 0)\end{array}$ & $\begin{array}{c}69 \cdot 6 \pm 5.7 \\
(29 \cdot 0-110 \cdot 0)\end{array}$ & $\begin{array}{c}77 \cdot 9 \pm 6 \cdot 8 \\
(47 \cdot 4-104 \cdot 0)\end{array}$ \\
\hline
\end{tabular}

Table 3. Relation of excretion of creatinine and hydroxyproline to change in length and in weight of nineteen marasmic male infants throughout recovery

\begin{tabular}{|c|c|c|c|c|c|c|}
\hline Subject & $\begin{array}{l}\text { Weight on } \\
\text { admission } \\
\text { (g) }\end{array}$ & $\begin{array}{l}\text { No, of } \\
\text { studies }\end{array}$ & $\begin{array}{c}\text { Change } \\
\text { in length } \\
(\mathrm{mm} / \mathrm{d})\end{array}$ & $\begin{array}{c}\text { Change } \\
\text { in weight } \\
(\mathrm{g} / \mathrm{d})\end{array}$ & $\begin{array}{l}\text { Mean Cre } \\
(\mathrm{mg} / \mathrm{d})\end{array}$ & $\begin{array}{l}\text { Mean OHPr } \\
(\mathrm{mg} / \mathrm{d})\end{array}$ \\
\hline $\mathbf{I}$ & 3580 & 7 & 0.92 & $3^{8 \cdot 6}$ & $62 \cdot 7$ & 18.5 \\
\hline 2 & 3920 & 6 & 0.83 & $32 \cdot 2$ & $43 \cdot 3$ & 16.6 \\
\hline 3 & $323^{\circ}$ & 7 & 0.98 & $3+9$ & $52 \cdot 7$ & $30 \cdot 1$ \\
\hline 4 & 4130 & 6 & 0.69 & $27 \cdot 7$ & $5 \mathrm{I} \cdot \mathrm{I}$ & $24 \cdot 3$ \\
\hline 5 & $345^{\circ}$ & 6 & 0.61 & $3 \times 7$ & $51 \cdot 6$ & $30 \cdot 3$ \\
\hline $\begin{array}{l}3 \\
6\end{array}$ & 3480 & 6 & 0.63 & $25 \cdot 2$ & $46 \cdot 2$ & $24 \cdot 4$ \\
\hline 7 & $345^{\circ}$ & 6 & 0.91 & $39 \cdot 4$ & $52 \cdot 5$ & $20 \cdot 3$ \\
\hline 8 & 3260 & 7 & 0.73 & $26 \cdot 0$ & $48 \cdot 4$ & $27 \cdot 6$ \\
\hline 9 & 4260 & 5 & 0.91 & $39 \cdot 0$ & $68 \cdot 7$ & $16 \cdot 5$ \\
\hline 10 & 4060 & 6 & 0.76 & 34.9 & 53.5 & $x 8 \cdot 2$ \\
\hline I I & 3920 & 7 & 0.61 & 35.4 & 90.9 & $29^{\circ} \mathrm{I}$ \\
\hline 12 & 4840 & 5 & 0.67 & $26 \cdot 7$ & $66 \cdot 9$ & $23 \cdot 4$ \\
\hline I3 & 4100 & 7 & 0.54 & $4 I \cdot 8$ & $78 \cdot 3$ & $27 \cdot 5$ \\
\hline 14 & 5200 & 7 & 0.38 & $2 I \cdot 0$ & $54 \cdot 1$ & $8 \cdot 5$ \\
\hline I 5 & 4920 & 5 & 0.88 & 66.7 & $69 \cdot 9$ & $14 \% 7$ \\
\hline 16 & 4380 & 7 & 0.75 & $44^{\circ} 9$ & $70 \cdot 1$ & $35 \cdot 2$ \\
\hline 17 & $425^{\circ}$ & 6 & 0.72 & 34.4 & $6 I \cdot 5$ & $35 \cdot I$ \\
\hline 18 & $495^{\circ}$ & 7 & 0.54 & $45 \cdot 8$ & $80 \cdot 2$ & $34 \cdot 3$ \\
\hline I9 & 4980 & 5 & 0.59 & $41 \cdot 9$ & $83 \cdot 1$ & $19^{\circ} \mathrm{I}$ \\
\hline
\end{tabular}

Andersen, Filer \& Fomon, 1967). Although there was considerable individual variation, mean values gradually approached, but did not reach, normal even after 4 months. There was no correlation of OHPr excretion with age of patient or with body-weight on admission.

Urinary Cre excretion ( $\mathrm{mg} / 24 \mathrm{~h}$ ) is also shown in Table 2. Values fluctuated considerably although the general trend was to increase. There was no relation to initial weight deficit or to age.

$O H P r$ and Cre excretion related to increase in height and weight. Table 3 shows the 
relationship between the mean of several determinations of OHPr and Cre excretion throughout recovery and the daily increase in length and weight for each of nineteen marasmic patients. There was a correlation between Cre excretion and weight increase $(r=0.5 \mathrm{I}, 0.0 \mathrm{I}<P<0.02)$ but none between $\mathrm{OHPr}$ and increase in length $(r=-0.13)$.

Cre excretion related to actual height and weight. Excretion of Cre during recovery of malnourished children was reported by Standard, Wills \& Waterlow (1959) and Picou, Alleyne \& Seakins ( 1965$)$ in terms of actual weight or height. Table 4 shows our results expressed in this way.

Table 4. Excretion of Cre in relation to actual height and weight of marasmic infants at intervals during recovery

\begin{tabular}{|c|c|c|c|c|c|c|c|}
\hline \multirow{2}{*}{$\begin{array}{l}\text { Time after } \\
\text { admission (d) }\end{array}$} & \multirow{2}{*}{$\begin{array}{l}\text { No. of } \\
\text { patients }\end{array}$} & \multicolumn{3}{|c|}{$\begin{array}{l}\text { Cre excretion in relation } \\
\text { to } \mathrm{ht}(\mathrm{mg} / \mathrm{cm} \mathrm{d})\end{array}$} & \multicolumn{3}{|c|}{$\begin{array}{l}\text { Cre excretion in relation } \\
\text { to wt }(\mathrm{mg} / \mathrm{kg} \mathrm{d})\end{array}$} \\
\hline & & Mean & $\mathrm{SE}$ & Range & Mean & $\mathrm{SE}$ & Range \\
\hline$\circ$ & 19 & 0.76 & 0.04 & $0.5^{I-I} \cdot 15$ & $X \times 17$ & 0.66 & $7 \cdot 93^{-8}-8 \cdot 36$ \\
\hline 15 & I 7 & 0.81 & 0.06 & $0.44-1.17$ & 10.81 & 0.68 & $5.80-6.83$ \\
\hline 30 & I9 & I.08 & 0.06 & $0.66-1.90$ & 12.60 & 0.80 & $7 \cdot 78-2 \times \cdot 4$ \\
\hline 45 & 19 & $I .00$ & 0.07 & $0.55-1.87$ & 10.74 & 0.74 & $6 \cdot 98-19 \cdot 17$ \\
\hline 60 & 17 & $x \cdot 13$ & 0.07 & $0.42-1.60$ & $I I \cdot 13$ & $0.7 \mathrm{I}$ & $4.22-15 \cdot 90$ \\
\hline 90 & 17 & $1 \cdot 12$ & 0.07 & $0.75-1.60$ & 9.98 & 0.47 & $6.97-13.00$ \\
\hline 120 & IO & $\mathrm{I} \cdot \mathrm{I}_{4}$ & 0.09 & $0.72-1 \cdot 50$ & $9 \cdot 54$ & 0.53 & $7 \cdot 29-12 \cdot 36$ \\
\hline
\end{tabular}

Diurnal variation. Results from different laboratories are inconsistent in showing whether or not values for OHPr: Cre ratio in 'spot' samples are representative of $24 \mathrm{~h}$ excretion (Howells \& Whitehead, 1967; Mohanram, Anasuya, Narasinga Rao \& Srikantia, 1969). If they are not, then the OHPr index is clearly inapplicable under field conditions. A total of sixty-four collections of urine was made over a $24 \mathrm{~h}$ period each in four consecutive 6-hourly samples. For each $6 \mathrm{~h}$ value compared with the $24 \mathrm{~h}$ value there was extremely high correlation of the OHPr index values (o- $6 \mathrm{~h}, r=0.963$; $7-12$ h, $r=0.950 ; 13-18$ h, $r=0.964 ;$ 19-24 h, $r=0.944$ ).

Cre excretion and urine volume. It has been suggested that variation in daily Cre excretion might be related to urine volume (Standard et al. 1959; Arroyave \& Wilson, I961). For I 8 samples taken throughout the period of treatment in the Unit multiple correlations between urine volume, body-weight and Cre were calculated. The coefficient of partial correlation of weight on Cre (0.719) was considerably greater than that of urine volume on Cre $(0.485)$.

\section{Anthropometry, diet, and Cre and OHPr excretion}

A subgroup of eleven male infants aged $3^{-5}$ months was chosen. All available males of this age were included. This approach was adopted in order to obtain as uniform a group as possible, since body composition and dietary requirements change considerably during the ist year of life. Linear regression analyses of OHPr and Cre excretion on all the somatic measurements and the dietary factors mentioned previously (p. 643) were carried out. Urinary excretions of OHPr and Cre (mg/24 h) were 
expressed as the change (increase or decrease) during the various $\mathrm{I} 5$ or $30 \mathrm{~d}$ periods. Values for rate of change in urinary excretion or somatic measurements were expressed in terms of increase or decrease per $24 \mathrm{~h}$. Dietary factors were also calculated in terms of mean daily value. The skinfold thickness value was the mean daily change during a period of measurements made in four sites. Neither urinary constituent was correlated consistently with any of the somatic measurements or dietary factors.

\section{Significance of diminished excretion of $\mathrm{OHPr}$ and Cre}

There is some evidence (Whitehead, 1967) that the OHPr index is lowered in relation to intercurrent infections. The present study provided an opportunity to gain more information on this subject by observing the changes in $\mathrm{OHPr}$ and Cre excretion at intervals during recovery, using results for $24 \mathrm{~h}$ samples. For the eleven marasmic male infants aged 3-5 months, there was a total of sixty periods of either I 5 or $30 \mathrm{~d}$ each for which the net changes in OHPr and Cre excretion were recorded by comparing values at the beginning and end of the periods. The occurrence of various infections was also noted in relation to these periods. There was a net lowering of Cre in twenty periods, of OHPr in fifteen, of both substances in fourteen periods, and of either in twenty-two. This is compatible with the high correlation, noted also by others (Anasuya \& Narasinga Rao, 1966), for Cre and OHPr excretion for all periods of sampling $(r=0.525 ; P<0.001)$.

Intercurrent infections were recorded in thirty, or half, of the periods. In these periods there was diminished OHPr excretion in ten, of Cre excretion in nine, and of both in eight, and of either in eleven. Thus, although excretion of either substance was diminished in twenty-two periods, only eleven, or half, of these were associated with infections. Similarly of the thirty periods with infections only eleven had diminished excretion of either substance. The periods of reduced excretion and of intercurrent infection were scattered throughout the entire admission period. There was no special association with any particular infection. Diminution of somatic measurements was infrequent in relation to diminished excretion (weight five periods, muscle mid-arm circumference eight, skinfolds five, mid-arm circumference two, and chest circumference two).

\section{OHPr and Cre concentrations in 'spot' samples}

'Spot' urine samples were obtained from fifty-seven preschool children at home, all members of families of a low socio-economic group in which a study is being made of 'failure to thrive'. On the day the urine sample was obtained the modified index of thriving was calculated for each child (Table $\mathrm{I}$ ). The OHPr and Cre values (m-moles/l) were expressed as what we here term the OHPr index for weight (age-adjusted). This was obtained by using the values shown in Fig. I.

The values in this figure at various ages were obtained by multiplying the values for the OHPr: Cre ratio of healthy children given by Allison, Walker \& Smith (1966) by the Boston Standard (5oth percentile) body-weight and height values. In this way standard OHPr indices for weight and for height were plotted at ages between $\mathrm{I} 2$ and 
60 months. The downward trend with age for both indices is clear and the difference between the highest and lowest point amounts to about $50 \%$ for the weight index and to over $80 \%$ for the height index. The latter is included only to show that it behaves similarly to the weight index. Most of the change takes place between 18 and 42 months, a critical period in assessing nutritional status.

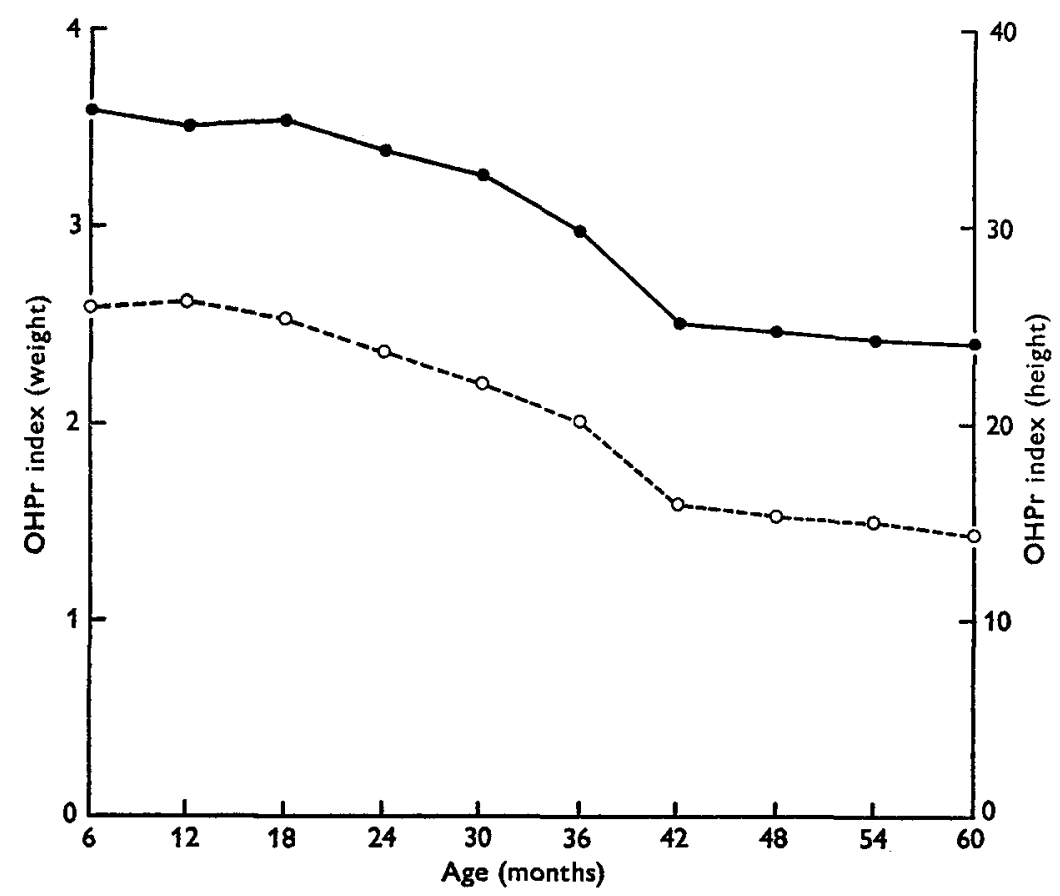

Fig. I. Effect of age on hydroxyproline index for weight $(--)$ and height $(\mathrm{O}---\mathrm{O})$. Indices at various ages calculated from OHPr: Cre values of Allison et al. (x g66) and Boston 5oth percentiles for weight and height. OHPr index for weight was adjusted for age by dividing it by the value for age in the figure, giving OHPr index (age-adjusted).

The OHPr index (age-adjusted) for each child was calculated by dividing the OHPr index according to Whitehead (1965) by the OHPr index for weight shown in Fig. I at the appropriate age.

For the fifty-seven field samples there was a highly significant inverse relationship between the OHPr index (age-adjusted) and the index of thriving (modified) $(r=-0.34 ; P<0.02)$.

In the same way OHPr index (age-adjusted) and index of thriving (modified) for the malnourished children in the Unit, male and female, throughout recovery were calculated. In all there were 194 observations. There was a highly significant inverse correlation between the OHPr index (age-adjusted) and the modified index of thriving $(r=-0.48 ; P<0.001)$. 
The results on severely marasmic infants support the evidence already reported in the literature that determinations on $24 \mathrm{~h}$ collections of urine show markedly lowered excretion of both OHPr and Cre in the acutely malnourished state. There is a gradual increase towards normal values with recovery, more regular for OHPr than for Cre. Even after 4 months of treatment, excretion remains subnormal compared with that for a child of the same chronological age, although it approximates to that for a child of the same height.

Picou et al. (1965) reported a greater excretion of OHPr in their mainly marasmickwashiorkor cases on recovery than found in our marasmic patients. They also found the lowest $\mathrm{OHPr}$ excretion in the children with the greatest deficit in body-weight for height. There was no such relationship in the present series.

In Table 3 the results for OHPr and Cre excretion in our patients in relation to increase in weight and length are expressed similarly to the results for $\mathrm{OHPr}$ excretion alone obtained by Younoszai et al. (1967) on normal infants aged 20-120 d. The significant correlation of OHPr excretion with length increase observed in their values did not occur in ours, suggesting that the compensatory growth during recovery from marasmus is not the same as normal growth. On the other hand, there was a significant correlation of Cre excretion with weight increase. Age on admission or severity of malnutrition, as judged by weight deficit, did not appear to influence excretion and did not explain the considerable individual variations.

The values in Table 4 for Cre excretion expressed in terms of $\mathrm{mg} / \mathrm{kg}$ per $\mathrm{d}$ or $\mathrm{mg} / \mathrm{cm}$ per $\mathrm{d}$ may be compared with two sets of results from Jamaica. Although the three sets of results are not strictly comparable it can be seen that the values obtained are of the same order. Whichever way the results are expressed, ours resemble those of Picou t al. (1965) most closely although at a generally lower level. This might be accounted for by a greater degree of muscular wasting in our children. The main difference between the two sets of values from Jamaica is the considerable rise in Cre output after day 60 in the study of Standard et al. (1959). This tendency was not observed in our results. It might have been related to the small number of cases studied at this time by Standard et al.

There is some doubt whether the close relationship which Cre excretion bears to muscle mass in health holds good in disease. In premature babies, body-weight and Cre excretion are not correlated at all (Cranny \& Cranny, I960), and Kennedy (196I) was unable to relate Cre excretion in children, who were convalescing from various diseases, to estimates of muscle mass based on body measurements, soft tissue radiographs or total exchangeable potassium. Large increases in Cre output in the early days of recovery, much greater than could be accounted for by increase in muscle mass, have been noted in kwashiorkor (Standard et al. 1959; Arroyave \& Wilson, 1961). Our results showed a greater dependence of Cre excretion on body-weight than on urinary volume. Recently, Alleyne ( 1968 ) found that, while there was a linear correlation between the $24 \mathrm{~h}$ urinary excretion of Cre and total body potassium in children recovering from malnutrition, calculations of the contribution of muscle potassium to 
total body potassium based on values for Cre excretion gave unexpected results which could best be explained by changes in muscle turn-over leading to alteration of the usual relationship of urinary Cre to muscle mass. Consequently it would appear to be unjustified to interpret a correlation between $24 \mathrm{~h}$ Cre excretion and increase in bodyweight, as in the present study, as reflecting a similar increase in muscle mass.

It was expected that in the subgroup of eleven similarly aged, rapidly growing marasmic infants relationships between the excretion of these substances and different measurements of growth and dietary intake would be revealed, if they existed. Few correlations had an $r$ value with $P<0.05$, and these were considered to be chance associations as there was no consistent pattern throughout the results.

The course of recovery from marasmus is punctuated by intercurrent infections (Garrow, Picou \& Waterlow, I962; McLaren, ı966; Rutishauser \& McCance, I968). From the present study it would appear that retardation of recovery, as reflected by diminished excretion of OHPr and Cre, occurs as frequently in the absence, as in the presence, of an overt infection. It is our impression that some of these incidents of diminished OHPr and Cre excretion may coincide with episodes of teething. These are very upsetting to the child, making it anorexic, fretful and causing loss of sleep. Frequently, several teeth, whose eruption has apparently been retarded by malnutrition, appear at once. The apparent depressing effect on $\mathrm{OHPr}$ excretion of mild infections found by Whitehead (1967) and ourselves and the high levels of excretion reported by Howells, Wharton \& McCance (1967) in seriously ill children make interpretation of results extremely difficult.

The remaining findings relate to the validity of the OHPr index introduced by Whitehead (1965). The justification for the use of this index has been given as follows: 'It was reasoned that the increase in creatinine excretion associated with growth would be compensated by the increase in body-weight and the index would reflect only changes in hydroxyproline excretion' (Whitehead, I966). Is this assumption justified? It is true that increase in weight will tend to offset the increase in Cre but not equally throughout the age period concerned. That age would have such an effect is implicit in the findings of Stearns, Newman, McKinley \& Jeans (1958). The healthy child increases steadily in muscularity from the ist to the 9 th year, increase in Cre excretion outstripping gain in weight during this period. Consequently the OHPr index will not 'reflect only changes in hydroxyproline excretion'. The way in which the OHPr index alters with age is shown in Fig. I. An index using height, advocated by Wharton, Howells \& McCance (1967), is influenced by age even more than an index using weight. The change with age is greater still if the formula of Graystone $\&$ Cheek (1968), OHPr/Cre $=2.32-0.025 \times$ height, is used. Consequently it is necessary to take age into account in calculating the OHPr index. Others have stressed the importance of age as a factor in relation to OHPr excretion (Leroy, 1967; Allison et al. I966). Differences in age composition of groups studied could explain some reported discrepancies (Howells et al. 1967). The inability of Howells \& Whitehead (1967) to find significant differences with age suggests that possibly something may have been at fault in the design of their experiment. For example, we wonder, in view of our own difficulty in getting controls, whether their subjects were truly normal, their numbers 
adequate and the ages of the subjects correctly known. Furthermore, from experience in this Unit we cannot agree that reliable results can be obtained by 'relatively unqualified laboratory staff'.

The representative nature of the results on 'spot' samples has to be proved before such results can be compared with those made on collections over $24 \mathrm{~h}$ or longer. 'That they are representative is claimed by some (Howells \& Whitehead, r967) but denied by others (Mohanram et al. 1969). Our own results lend strong support to the contention that 'spot' samples are representative, but more work is needed on this point.

The necessity to take age into account when the index is used should not make for serious difficulty in practice since the age in months need be only approximately known. The OHPr index (age-adjusted) was found to correlate with our modified index of thriving in a group of children at home and also for marasmic infants recovering in the Unit. All that one can deduce from this is that the two indices are probably influenced by similar factors. In themselves, the physical dimensions attained by children would seem to be more important as an indication of their health than the amount of OHPr and Cre the children excrete, and physical dimensions are also much easier to determine.

At the present time attention is being given at the international level to possible use of the OHPr index and a number of other tests in the field (Whitehead, 1969). One such study has been published (Rutishauser \& Whitehead, I 969). Our experience with the OHPr index suggests that, even if all precautions are taken to avoid the pitfalls to which we have drawn attention, the objective will still not be achieved because of the complex aetiological factors, poor control over the experimental situation, and our lack of knowledge of the nature of the underlying metabolic processes.

This work was supported by U.S.P.H.S. Grant AM-05285 to the Institute of Nutrition Sciences, Columbia University, New York. The patients in the Unit were under the medical care of Dr Nadra Haddad Abu-Feisal and the nursing care of Mrs Mary Gheblikian and Miss Sirarpi Khalarian. The staff of the Computer Center of the University assisted with the statistical analyses.

\section{REFERENCES}

Alleyne, G. A. O. (1968). Clin. Sci. 34, 199.

Allison, D. J., Walker, A. \& Smith, Q. T. (1966). Clinica chim. Acta 14, 729.

Anasuya, A. \& Narasinga Rao, B. S. (1966). Indian f. med. Res. 54, 849 .

Arroyave, G. \& Wilson, D. (I96r). Am. J. clin. Nutr. 9, 170.

Cranny, R. L. \& Cranny, C. L. (1960). Am. F. Dis. Child. 99, 507.

Garrow, J. S., Picou, D. \& Waterlow, J. C. (1962). W. Indian med. F. Ir, 2 I7.

Graystone, J. A. \& Cheek, D. B. (1968). In Human Growth: Body Composition, Cell Growth, Energy, and Intelligence p. 221 [D. B. Cheek, editor]. Philadelphia: Lea and Febiger.

Howells, G. R., Wharton, B. A. \& McCance, R. A. (1967). Lancet i, ro82.

Howells, G. R. \& Whitehead, R. G. (1967). F. med. Lab. Technol. 24, 98.

Jelliffe, D. B. (1966). Monograph Ser. W.H.O. no. 53.

Kanawati, A. A., McLaren, D. S. \& Abu-Jawdeh, I. (1970). Proc. int. Congr. trop. Med. Malar. viII. Teheran, Iran 1968. (In the Press.)

Kennedy, W. P. (1961). Archs Dis. Childh. 36, 325.

Kivirikko, K. I., Laitinen, O. \& Prockop, D. J. (1967). Analyt. Biochem. 19, 249.

Leroy, E. C. (1967). Adv. clin. Chem. ro, 2 1 3. 
McLaren, D. S. (I966). Lancet ii, 485 .

McLaren, D. S., Kamel, W. W. \& Ayyoub, N. (1965). Am. F. clin. Nutr. 17, 152.

McLaren, D. S., Pellett, P. L. \& Read, W. W. C. (I967). Lancet i, 533.

Mohanram, M., Anasuya, A., Narasinga Rao, B. S. \& Srikantia, S. G. (1969). Lancet i, roz.

Picou, D., Alleyne, G. A. O. \& Seakins, A. (1965). Clin. Sci. 29, 517.

Rutishauser, I. H. E. \& McCance, R. A. (1968). Archs Dis. Childh. 43, 252.

Rutishauser, I. H. E. \& Whitehead, R. G. (1969). Br. F. Nutr. 23, I.

Standard, K. L., Wills, V. G. \& Waterlow, J. C. (1959). Am. F. clin. Nutr. 7, 27 I.

Stearns, G., Newman, K. J., McKinley, J. B. \& Jeans, P. C. (1958). Ann. N. Y. Acad. Sci. 69, 857.

Stuart, H. C. \& Stevenson, S. S. (1959). In Textbook of Pediatrics 7th ed., pp. 12-6I [W. Nelson, editor]. Philadelphia: Saunders.

Taussky, H. H. (1956). Clinica chim. Acta r, 2 ro.

Wharton, B. A., Howells, G. R. \& McCance, R. A. (1967). Nature, Lond. 2r5, 968.

Whitehead, R. G. (1964). Lancet i, 250.

Whitehead, R. G. (1965). Lancet ii, 567.

Whitehead, R. G. (1966). Lancet i, 203 .

Whitehead, R. G. (1967). Archs Dis. Childh. 42, 479.

Whitehead, R. G. (1969). Lancet i, ro3.

Younoszai, M. K., Andersen, D. W., Filer, L. J. \& Fomon, S. J. (1967). Pediat. Res. I, 266. 